\title{
STUDY OF CORRELATION BETWEEN SEVERITY OF ISCHEMIC MITRAL VALVE REGURGITATION BY ECHO DOPPLER AND ECG CHANGES IN ACUTE MYOCARDIAL INFARCTION
}

\author{
By \\ Mohamed Gamal Abd El-Azeem, Yasser Radwan Mohammed and \\ Yasser Al-Sayed Mohammed \\ Department of Cardiology, Faculty of Medicine Al-Azhar University \\ Corresponding author: Mohamed Gamal Abd El-Azeem, \\ E-mail: mohamed_gamal@gmail.com
}

\begin{abstract}
Background: Myocardial infarction (MI) accompanies with different mechanical complications including ischemic mitral regurgitation (IMR) which is correlated with increased risk of mortality and heart failure. IMR existence and its severity had significant prognostic effect on patients' mortality following acute myocardial infarction (AMI). Echocardiography is the choice imaging modality for the diagnosis and assessment of IMR and establishing its etiology. IMR usually results from papillary muscle displacement, ventricular dilation and remodeling with reduced closing forces.
\end{abstract}

Objective: Assessment of the correlation between echocardiographic severity of ischemic mitral valve regurgitation following acute myocardial infarction and its electrocardiographic location.

Patients and methods: This was a prospective study that included 100 patients admitted to CCU OF Beni-Suief General Hospital in the period from October 2019 to May 2020 . Those patients were divided on two equal groups: Group I: patients with STEMI and no, trivial or mild MR and Group II: patients with STEMI and moderate or severe MR.

Results: Mean age of group I involved in the study was $55.44 \pm 7.23$ years and $70 \%$ of them were males. Mean age of group II was $58.38 \pm 7.8$ and $56 \%$ were males. $70 \%$ of the group II had inferolateral STEMI compared to group I who had more anterior STEMI. Group II were more smokers with hyperlipidemia. Group II was with higher previous stable and unstable angina, with less streptokinase treatment, with higher abnormal chest radiogrgh and higher killip class. Group II had significantly lower EF and higher LVEDD, LVESD, LA diameter, RV diameter, MV A velocity, tricuspid valve excursion TAPSI and pulmonary artery pressure and more diastolic dysfunction. Mechanism of IMR in case group was mono leaflet tethering in 43 cases, both leaflet tethering in 7 cases and ring dilation in 30 cases. MR jet direction was medial commissure posterior in $31(62 \%)$, lateral commissure anterior in 12 (24\%), and both commissures central in 7 (14\%) cases.

Conclusion: Mitral regurgitation is common after acute myocardial infarction, especially in cases with inferior mitral regurgitation. The echocardiographic findings are indicative of left ventricular remodeling and abnormality of mitral valve apparatus.

Keywords: Ischemic Mitral Valve Regurgitation, Echo Doppler, ECG, Myocardial Infection. 


\section{INTRODUCTION}

Ischemic mitral regurgitation (IMR) is one of the most important coronary artery disease complications and, in particular, myocardial infarction (MI). The risk stratification of AMI patients during the early stage can identify high-risk patients, who require more advanced treatment and whose outcome can be improved through early intervention (Fazlinezhad et al., 2014).

Ischemic mitral regurgitation (IMR) is a subtype of secondary mitral regurgitation (MR), which is a complication of ischemic heart disease. Valvular involvement can be primary (organic) or secondary (functional). Primary occurs after the rupture of the mitral subvalvular apparatus in the context of an AMI. Secondary is when the valve leaflets and chordae are structurally normal and MR results from an imbalance between closing and tethering forces on the valve secondary to alterations in the left ventricle (LV) geometry (Lancellotti et al., 2013).

Ischemic mitral regurge is characterized mechanistically by incomplete mitral leaflet closure, namely displacement of the leaflet coaptation apically within the LV cavity. Although a spectrum of anatomic abnormalities of both LV and PMs exists, evidence points to a predominant role of "tethering" as the final common pathway in inducing IMR. Post- infarct, outward displacement of PMs Leads to stretching of the chordae tendinae and increased tethering forces on the mitral leaflets, which causes the apical coaptation and restricted closure. Annular dilatation may also contribute by stretching leaflets and causing incomplete closure. Practitioners should mindful not to classify as IMR those patients with mitral regurgitation and comorbid ischemic heart disease if there is any intrinsic mitral valve apparatus abnormality and/or there has not been a history of myocardial infarction (Nishimura et al., 2014).

However, functional ischemic MR is a highly dynamic lesion that may improve over time after coronary revascularization or impair because of progressive adverse left ventricular (LV) remodeling and tethering of the mitral leaflets (Chua et al., 2010). Furthermore, ischemic MR, contributing to LV volume overload, can exacerbate the adverse LV remodeling after STEMI, promoting further LV dilatation and, as in a vicious circle, further MR (Uddin et al., 2012).

Echocardiography is the choice imaging modality for the diagnosis and assessment of IMR and establishing its etiology (Lancellotti et al., 2013). IMR usually results from papillary muscle displacement, ventricular dilation and remodeling with reduced closing forces (Boyd, 2013).

Left ventricular (LV) remodelling after myocardial infarction (MI) can lead to apical and posterior displacement of the papillary muscles with resulting malcoaptation of the mitral leaflets and valvular insufficiency (Meris et al., 2012).

The present work aimed to assess the correlation between echocardiographic severity of ischemic mitral valve regurgitation following acute myocardial infarction and its electrocardiographic location. 


\section{PATIENTS AND METHODS}

This was a prospective study that included 100 patients admitted to $\mathrm{CCU}$ OF Beni-Suief General Hospital in the period from October 2019 to May 2020 .These patients were divided on two equal groups: Group I patients with STEMI and no, trivial or mild MR and Group II: patients with STEMI and moderate or severe MR.

Inclusion criteria: Patients presented with acute STEMI with: No previous history of MI, no previous percutaneous coronary intervtion (PCI), not performing PCI before echocardiography during the admission, no previous coronary artery bypasse surgery (CABG), no history of valvular or congenital heart disease and no echocardiographic finding of organic valve lesion.

Exclusion criteria: Patients presented with acute STEMI and history of previous MI, history of previous percutaneous coronary intervtion (PCI), history of performing PCI before echocardiography during the admission, history of previous coronary artery bypasse surgery (CABG), history of valvular or congenital heart disease and echocardiographic finding of organic valve lesion.

\section{All patients were subjected to:}

\section{Full history taking that included:}

Age, gender diabetes mellitus, hypertension, Cigarette smoking, dyslipidemia, previous stable angina, previous unstable angina, exertional dyspnea, treatment with streptokinase during admission.
II. Clinical examination: Examination included the estimation of heart rate, rhythm, pulse volume, respiratory rate, blood pressure, temperature, additional heart sounds, murmurs, pericardial rub and pulmonary rales.

Killip class was determined: Class I includes individuals with no clinical signs of heart failure. Class II includes individuals with rales or crackles in the lungs, an S3, and elevated jugular venous pressure. Class III describes individuals with frank acute pulmonary edema. Class IV describes individuals in cardiogenic shock or hypotension.

\section{III- Investigations:}

A. 12-lead electrocardiograms: 12-lead electrocardiogram was recorded at admission to diagnose STEMI and determine its site (inferior, anterior, lateral, posterior, and right) by determining the leads exhibiting ST segment elevation.

B. Chest X-ray: Chest radiograph was done searching for congestion, pulmonary oedema, cardiomegaly or other causes of chest pain.

\section{Transthoracic echocardiogram:} Transthoracic two-dimensional imaging and pulsed wave Doppler echocardiographic studies were obtained in all patients using. a commercially available ATL HDI 5000 echocardiographic machine with a broadband $2.5-4 \mathrm{MHz}$ phased array transducer.

Patients were examined in the supine and left lateral positions to obtain adequate images in the parasternal long and short axis views, the four, five and two chamber apical 
views, the apical long axis as well as in the subcostal views. Transthoracic echocardiography was performed at rest during the first 5 days after AMI.

\section{Echocardiographic:}

- Left ventricular ejection fraction (LVEF).

- Right ventricular function.

- Regional wall motion abnormality (RWMA).

- Mitral inflow.

- Left atrium, left ventricle, right ventricle size and aortic root diameter.

- Pulmonary artery pressure from tricuspid valve regurge velocity.

When the valve structure intrinsically was normal and the regurgitation was caused as a result of the myocardial infarction and the ischemic MR was diagnosed. Other parameters for assessing MR were measured to classify MR as mild, moderate or severe MR as:

- LV annular diameter,

- Leaflet tethering and tethering depth,

- Direction of MR jet,

- Vena contracta width,

- Effective Regurgitant orifice area,

- PISA radius,
- MR regurgitant volume.

MR severity and correlation to the site of MI in the ECG was determined.

D. Labarotory investigations: Routine blood tests like CBC\& kidney function tests, lipid profile and cardiac troponin were done.

Ethical consideration: Participation in this study was voluntary and gave written consents to share in this work. The study was approved from ethical committee of AL-Azhar University hospital.

\section{Statistical Analysis:}

All data were subjected to revision and validation then description and analysis on IBM-compatible PC by using SPSS (Statistical Package for the Social Sciences) program version 22.0.0, Microsoft Office Excel 2007, and GraphPad Prism 6. Descriptive statistics were performed for all studied parameters in the three studied groups and were presented in the form of mean, standard deviation (SD), minimum, maximum, range, and percentages. Analytical comparison between different groups was done by using student $t$ test for comparing parametric data when normally distributed. $\mathrm{P}<0.05$ was considered significant.

\section{RESULTS}

Mean age of group I involved in the study was $55.44 \pm 7.23$ years. $70 \%$ of them were males.
Mean age of group II was $58.38 \pm$ $7.8,56 \%$ were males. Clinical risk factors among the study 
populations were investigated and we found that group II was more smokers with hyperlipidemia. Comparison of the ECG between the 2 groups showed statistically significant difference according to the site of MI where $70 \%$ of group II had inferolateral STEMI compared to the group I who had more anterior STEMI .By clinical history, examination and investigations there was statistically significant difference found between two groups regarding and treatment with Sreptokinase, Normal chest $\mathrm{x}$ - ray and killip class. But there was no statistically significant difference found between two groups regarding Previous Stable Angina and Pervious Un Stable Angina. Group II was with higher previous stable and unstable angina, with less streptokinase treatment, with higher abnormal chest radiogrgh and higher killip class (Table 1)

Table (1): Comparison between the two studied groups according to demographic data, risk factors, MI type and clinical data

\begin{tabular}{|c|c|c|c|c|c|c|}
\hline \multirow{2}{*}{\multicolumn{2}{|c|}{ Groups }} & \multicolumn{2}{|c|}{$\begin{array}{c}\text { Group I } \\
(\mathbf{n}=\mathbf{5 0})\end{array}$} & \multicolumn{2}{|c|}{$\begin{array}{c}\text { Group II } \\
(\mathbf{n}=\mathbf{5 0})\end{array}$} & \multirow[t]{2}{*}{$\mathbf{P}$} \\
\hline & & No. & $\%$ & No. & $\%$ & \\
\hline & 35.0 & 70.0 & 28.0 & 56.0 & 0.147 \\
\hline \multicolumn{2}{|l|}{$\begin{array}{l}\text { Male } \\
\text { Female }\end{array}$} & 15.0 & 30.0 & 22.0 & 44.0 & \\
\hline \multicolumn{2}{|l|}{$\begin{array}{l}\text { Age (years) } \\
\text { Min. - Max. } \\
\text { Mean } \pm \text { SD. }\end{array}$} & \multicolumn{2}{|c|}{$\begin{array}{r}41.0-75.0 \\
55.44 \pm 7.23 \\
\end{array}$} & \multicolumn{2}{|c|}{$\begin{array}{l}42.0-75.0 \\
58.38 \pm 7.8\end{array}$} & 0.054 \\
\hline $\begin{array}{l}\text { Diabetes Mellitus } \\
\text { (DM) }\end{array}$ & $\begin{array}{l}\text { No } \\
\text { Yes }\end{array}$ & $\begin{array}{l}38 \\
12\end{array}$ & $\begin{array}{l}76.0 \% \\
24.0 \%\end{array}$ & $\begin{array}{l}33 \\
17\end{array}$ & $\begin{array}{l}66.0 \% \\
34.0 \%\end{array}$ & 0.271 \\
\hline Hypertension (HTN) & $\begin{array}{l}\text { No } \\
\text { Yes }\end{array}$ & $\begin{array}{l}26 \\
24\end{array}$ & $\begin{array}{l}52.0 \% \\
48.0 \%\end{array}$ & $\begin{array}{l}22 \\
28\end{array}$ & $\begin{array}{l}44.0 \% \\
56.0 \%\end{array}$ & 0.423 \\
\hline Hyperlipidemia & $\begin{array}{l}\text { No } \\
\text { Yes }\end{array}$ & $\begin{array}{l}36 \\
14\end{array}$ & $\begin{array}{l}72.0 \% \\
28.0 \%\end{array}$ & $\begin{array}{l}40 \\
10 \\
\end{array}$ & $\begin{array}{l}80.0 \% \\
20.0 \% \\
\end{array}$ & 0.349 \\
\hline Smoking & $\begin{array}{l}\text { No } \\
\text { Yes }\end{array}$ & $\begin{array}{l}33 \\
17\end{array}$ & $\begin{array}{l}66.0 \% \\
34.0 \%\end{array}$ & $\begin{array}{l}32 \\
18\end{array}$ & $\begin{array}{l}64.0 \% \\
36.0 \%\end{array}$ & 0.834 \\
\hline M.I Type & $\begin{array}{l}\text { Anterior } \\
\text { Inferolateral }\end{array}$ & $\begin{array}{l}27 \\
23\end{array}$ & $\begin{array}{l}54.0 \% \\
46.0 \%\end{array}$ & $\begin{array}{l}15 \\
35\end{array}$ & $\begin{array}{l}30.0 \% \\
70.0 \%\end{array}$ & 0.015 \\
\hline $\begin{array}{l}\text { Previous Stable } \\
\text { Angina }\end{array}$ & $\begin{array}{l}\text { No } \\
\text { Yes }\end{array}$ & $\begin{array}{c}45 \\
5\end{array}$ & $\begin{array}{l}90.0 \% \\
10.0 \%\end{array}$ & $\begin{array}{l}38 \\
12\end{array}$ & $\begin{array}{l}76.0 \% \\
24.0 \%\end{array}$ & 0.062 \\
\hline $\begin{array}{l}\text { Pervious UnStable } \\
\text { Angina }\end{array}$ & $\begin{array}{l}\text { No } \\
\text { Yes }\end{array}$ & $\begin{array}{c}47 \\
3\end{array}$ & $\begin{array}{l}94.0 \% \\
6.0 \%\end{array}$ & $\begin{array}{c}42 \\
8\end{array}$ & $\begin{array}{l}84.0 \% \\
16.0 \%\end{array}$ & 0.110 \\
\hline Normal chest $\mathrm{x}$ ray & $\begin{array}{l}\text { No } \\
\text { Yes }\end{array}$ & $\begin{array}{l}14 \\
36 \\
\end{array}$ & $\begin{array}{l}28.0 \% \\
72.0 \% \\
\end{array}$ & $\begin{array}{l}27 \\
23 \\
\end{array}$ & $\begin{array}{l}54.0 \% \\
46.0 \% \\
\end{array}$ & 0.001 \\
\hline Killip class & \begin{tabular}{|l} 
I \\
II \\
III \\
\end{tabular} & $\begin{array}{c}43 \\
7 \\
0\end{array}$ & $\begin{array}{l}86.0 \% \\
14.0 \% \\
0.0 \% \\
\end{array}$ & $\begin{array}{c}24 \\
18 \\
8 \\
\end{array}$ & $\begin{array}{l}48.0 \% \\
36.0 \% \\
16.0 \% \\
\end{array}$ & 0.001 \\
\hline $\begin{array}{l}\text { Treatment With } \\
\text { Sreptokinase }\end{array}$ & $\begin{array}{l}\text { No } \\
\text { Yes }\end{array}$ & $\begin{array}{l}11 \\
39\end{array}$ & $\begin{array}{l}22.0 \% \\
78.0 \%\end{array}$ & $\begin{array}{l}23 \\
27\end{array}$ & $\begin{array}{l}46.0 \% \\
54.0 \%\end{array}$ & 0.011 \\
\hline
\end{tabular}

By echocardiography group II had significantly lower Ejection Fraction $(\mathrm{cm})$, LA Diameter $(\mathrm{cm})$, Aortic root Diameter (cm), RV Diameter (cm), MV A $(\mathrm{EF} \%)$ and higher LVEDD $(\mathrm{cm})$, LVESD velocity $(\mathrm{m} / \mathrm{sec})$, tricuspid valve excursion 
TAPSI $(\mathrm{cm})$ and pulmonary artery pressure PAP (mmHg).Tissue Doppler findings were also significantly different between the two groups. Group II had RWMA more in RCA territory while group I more in LAD territory.

Mechanism of IMR in case group was mono leaflet tethering in 43 cases, both leaflet tethering in 7 cases and ring dilatation in 30 cases. MR jet direction was medial commissure posterior in 31 (62\%), lateral commissure anterior in 12 (24\%) and both commissures central in 7 (14\%-. Table 2).

Table (2): Comparison between the two studied groups according to echocardiographic data

\begin{tabular}{|c|c|c|c|c|}
\hline \multirow{2}{*}{\multicolumn{2}{|c|}{$\begin{array}{ll}\text { Parameters } & \text { Groups } \\
\end{array}$}} & \multirow{2}{*}{$\begin{array}{l}\text { Group I } \\
\text { No.= 50 }\end{array}$} & \multirow{3}{*}{$\begin{array}{c}\text { Group II } \\
\text { No. }=\mathbf{5 0} \\
45.92 \pm 8.49\end{array}$} & \multirow{3}{*}{$\begin{array}{c}\begin{array}{c}\text { P- } \\
\text { value }\end{array} \\
0.003\end{array}$} \\
\hline & & & & \\
\hline $\mathrm{EF}(\%)$ & Mean \pm SD & $51.1 \pm 8.76$ & & \\
\hline LVEDD $(\mathrm{cm})$ & Mean \pm SD & $4 \pm 0.49$ & $5.04 \pm 0.63$ & 0.001 \\
\hline $\operatorname{LVESD}(\mathrm{cm})$ & Mean \pm SD & $2.91 \pm 0.47$ & $3.8 \pm 0.51$ & 0.001 \\
\hline Posterior wall thickness $(\mathrm{cm})$ & Mean \pm SD & $0.87 \pm 0.13$ & $0.88 \pm 0.14$ & 0.651 \\
\hline $\begin{array}{l}\text { Septal Wall } \\
\text { Thikness }(\mathrm{cm})\end{array}$ & Mean \pm SD & $0.92 \pm 0.13$ & $0.92 \pm 0.15$ & 0.889 \\
\hline LA Diameter $(\mathrm{cm})$ & Mean \pm SD & $2.57 \pm 0.36$ & $3.89 \pm 0.35$ & 0.001 \\
\hline $\begin{array}{l}\text { Aortic root } \\
\text { Diameter }(\mathrm{cm})\end{array}$ & Mean \pm SD & $2.6 \pm 0.36$ & $3.11 \pm 0.29$ & 0.001 \\
\hline RV Diameter $(\mathrm{cm})$ & Mean \pm SD & $2.74 \pm 0.26$ & $2.92 \pm 0.16$ & 0.001 \\
\hline MV A velocity (m/sec) & Mean \pm SD & $0.8 \pm 0.14$ & $0.97 \pm 0.26$ & 0.001 \\
\hline MV E velocity (m/sec) & Median(IQR) & $0.90(40-60)$ & $1(40-60)$ & 0.016 \\
\hline $\mathrm{E} / \mathrm{A}$ & Mean \pm SD & $1.15 \pm 0.29$ & $1.1 \pm 0.28$ & 0.005 \\
\hline MAPSI $(\mathrm{cm})$ & Mean \pm SD & $1.01 \pm 0.18$ & $0.91 \pm 0.17$ & 0.005 \\
\hline \multirow{2}{*}{ RWMA } & RCA & $23(46 \%)$ & $35(70 \%)$ & \multirow{2}{*}{0.015} \\
\hline & LAD & $27(54 \%)$ & $15(30 \%)$ & \\
\hline TAPSI $(\mathrm{cm})$ & Mean \pm SD & $1.77 \pm 0.21$ & $1.9 \pm 0.22$ & 0.003 \\
\hline PAP $(\mathrm{mmHg})$ & Median(IQR) & $25(40-60)$ & $48(40-60)$ & 0.001 \\
\hline EROA (CM2) & Mean \pm SD & - & $20.40 \pm 1.98$ & - \\
\hline $\begin{array}{l}\text { MV Regurgitant } \\
\text { volume (ML) }\end{array}$ & Mean \pm SD & - & $27.86 \pm 5.32$ & - \\
\hline Vena Contracta (mm) & Mean \pm SD & - & $6.28 \pm 1.9$ & - \\
\hline PISA diameter $(\mathrm{ml})$ & Mean \pm SD & - & $1.04 \pm 0.24$ & - \\
\hline Tenting Area $(\mathrm{cm} 2)$ & Mean \pm SD & - & $1.59 \pm 0.34$ & - \\
\hline MV Annulus diameter $(\mathrm{cm})$ & Mean \pm SD & - & $3.97 \pm 0.32$ & - \\
\hline \multirow{2}{*}{ Leaflet Tethering } & Both & - & $7(14.0 \%)$ & \multirow[b]{2}{*}{-} \\
\hline & Mono & - & $43(86.0 \%)$ & \\
\hline \multirow{3}{*}{ Jet Direction } & Anterior & - & $12(24.0 \%)$ & - \\
\hline & Central & - & $7(14.0 \%)$ & - \\
\hline & Posterior & - & $31(62.0 \%)$ & - \\
\hline
\end{tabular}

MVE \&PAP are not normally distributed. So, we used another test (Mann-Whitney test) and found group II median higher than group I regarding PAP \& MVE.

DISCUSSION
In our study, we observed that cases with IMR are more male, older and smoker. Being male, smoker and old age, 
these are risk factors to IHD and its complication. Males were more dominant in cases of $\operatorname{IMR}(70 \%)$ in the study of Clinical implications of early mitral regurgitation in patients with reperfused acute myocardial infarction (Carrabba et al., 2010) .male was the dominant sex regarding frequency $(72 \%)$ in a study about the frequency of IMR after first time acute MI and its relation to infarct location and in-hospital mortality (Fazlinezhad et al., 2014).

Valuckiene et al. (2015) had found that more cases were females and smokers when studied the relation between IMR and acute MI. MacHaalany et al. (2014), had also found that more cases with IMR were females and smokers when they studied predictors and prognosis of IMR in the era of PCI.

The differences between the groups regarding the IMR severity are related to different baseline characteristics, coronary artery risk factors, and time of performing echocardiography (Fazlinezhad et al., 2014).

In our study, we observed that $70 \%$ of the Group II had inferolateral STEMI compared to the other group who had more anterior STEMI. So, moderate to severe IMR was more common with inferior MI, the occurrence and severity of the IMR was affected by the location of MI. The mechanism producing IMR was different in anterior compared with inferior STEMI. Although LV remodeling and global LV dysfunction was greater in anterior MI, IMR was more severe in inferior STEMI due to the increased tethering force of the posteromedial papillary muscle near the site of the infarction. Posteromedial papillary muscle has a single blood supply, while anterolateral papillary muscle has a dual blood supply so posteromedial papillary muscle is easily affected by occlusion of its artery in inferior MI.

Valuckiene et al. (2015), in the study of IMR in acute phase of MI, also reported that IMR is more common in inferior MI. Mentias et al. (2016), in the study of outcomes of ischemic mitral regurgitation in anterior versus inferior ST elevation myocardial infarction, reported that IMR is more common in inferior MI.

Chua et al. (2011) have found that factors associated with a significantly higher risk of positive IMR included advanced age, Killip class $\geq 3$, increased left atrial diameter, increased LV end diastolic volume, and isolated inferior MI. When MI type (isolated inferior over isolated anterior) was used as a covariate, patients with an isolated inferior MI were 2.37 times more likely to have moderate or severe IMR than those with an anterior MI. Fazlinezhad et al. (2014) had reported that anterior and anterolateral walls were the most common territories of $\mathrm{MI}$ in patients with or without IMR.

In our study, patients in group II were more smokers with hyperlipidemia and there was no statistical difference regarding diabetes mellitus and hypertension. Smoking, hyperlipidemia, diabetes mellitus and hypertension are major risk factors for coronary artery disease and can influence its course and complications, but in our study we did not find any statistically difference regarding diabetes and hypertension and this may be due to small number of patients in our study. 
Pant et al. (2011) reported that ischemic mitral regurgitation and diabetes or hypertension was not significantly related. Also, clinical significance of mitral regurgitation after acute myocardial infarction, had reported that IMR and diabetes or hypertension was not significantly related. They did not find a significant association of functional ischemic MR with age, sex or any of the conventional risk factors alone.

In our study, Group II was with higher previous stable and unstable angina, with less streptokinase treatment, with higher abnormal chest radiogrgh and higher killip class. We found that previous history of stable and unstable angina was more with cases of moderate to severe IMR. We also found that streptokinase treatment was less in cases of moderate or severe IMR. So, treatment with streptokinase may decrease the severity of IMR. This was supported by Poh et al. (2012) as they found that both thrombolytic therapy and primary PCI were associated with decreased incidences of IMR following inferoposterior STEMI. It was also supported by Mehrnoush et al. (2018) who found that cases of moderate or severe IMR are less frequently treated with streptokinase.

We also found that cases with moderate or severe IMR had higher abnormal chest radiogrgh and higher killip class pointing to their more susceptibility to heart failure and its complication with bad prognosis. Fazlinezhad et al. (2014) observed higher rate of LVEF $<35 \%$ in the patients with IMR. MacHaalany et al. (2014) also reported Lower LVEF in the cases with moderate to severe IMR. This was supported by Mehrnoush et al. (2018) who reported that cases with IMR had significantly higher Killip class and lower LVEF.

In our study, group II had significantly lower EF and higher LVEDD, LVESD, LA diameter, RV diameter, MV A velocity, tricuspid valve excursion TAPSI and pulmonary artery pressure and more diastolic dysfunction.

Different echocardiographic findings are reported in cases with moderate to severe IMR. Fazlinezhad et al. (2014) reported higher grade of diastolic dysfunction, end-diastolic LV pressure in IMR cases. They also had higher Systolic Pulmonary Artery Pressure (SPAP) which was related directly to the severity of MR. MacHaalany et al. (2014) also showed higher prevalence of PAP, LVESD and LA size in moderate to severe IMR. It was reported that moderate and severe MR in acute MI is related to increased left ventricular diastolic dimensions (Valuckienè et al., 2015). Mehrnoush et al. (2018) also reported that LVEDV, LVEDVI, LVESV and LVESVI were mild to moderately enlarge which are predictable considering the local remodeling as a consequence of RWMA and papillary muscle displacement in inferior MI with IMR.

In our study, mechanism of IMR in group II was mono leaflet tethering in 43 cases, both leaflet tethering in 7 cases and ring dilatation in 30 cases.

The concept of PM dysfunction was based on clinical observations that ischemic MR occurred after inferior myocardial infarction and secondary dysfunction of the medial PM. Historically, the mechanism of chronic IMR was attributed to papillary muscle 
dysfunction. However, further studies demonstrated that ischemia of papillary muscles themselves fails to produce significant MR without damage of the underlying myocardial wall (Thomas et al., 2010). Our study was supported by Mehrnoush et al. (2018) who demonstrated that mono leaflet tethering and ring dilatation were the main contributers in IMR. MR jet direction was medial commissure posterior in 31 (62\%), lateral commissure anterior in $12(24 \%)$ and both commissures central in 7 (14\%). This was supported by Mehrnoush et al. (2018) who demonstrated that MR jet direction was posterior in most cases of moderate and severe IMR.

\section{CONCLUSION}

Ischemic mitral regurgitation (IMR) was common after acute myocardial infarction which has a great impact on the survival and development of post-MI heart failure. Its existence was associated with a higher mortality compared to those patients who do not develop MR, being directly related to its severity. There was a correlation between severity of ischemic of IMR and the site of myocardial infarction. This study showed that the incidence of IMR in inferior MI is higher than other types. The echocardiographic findings were indicative of left ventricular remodeling and abnormality of mitral valve apparatus.

\section{REFERENCES}

1. Boyd JH. (2013): Ischemic mitral regurgitation, where do we stand? Circ J., 77(8):1952-6.

2. Carrabba N, Parodi G, Valenti R, Shehu M, Migliorini A, Memisha G, Santoro GM and Antoniucci D. (2010): Clinical implications of early mitral regurgitation in patients with reperfused acute myocardial infarction. J Card Fail., 14:48-54.

3. Chua S, Hung J and Chung SY. (2011): Primary Percutaneous Coronary Intervention Lowers the Incidence of Ischemic Mitral Regurgitation in Patients With Acute ST-Elevated Myocardial Infarction. Circulation, 123:1529-1536.

4. Fazlinezhad A, Dorri M, Azari A and Bigdelu L. (2014): Frequency of Ischemic Mitral Regurgitation after First-Time Acute Myocardial Infarction and its Relation to Infarct Location and InHospital Mortality. J Teh Univ Heart Ctr., 9(4):160-165.

5. Lancellotti P, Troisfontaines P, Toussaint A and Pierard LA. (2013): Prognostic Importance of ExerciseInduced Changes in Mitral Regurgitation in Patients with Chronic Ischemic Left Ventricular Dysfunction. Circulation, 108(14):1713-7.

6. MacHaalany J, Bertrand OF, O'Connor K, Abdelaal E, Voisine $P$ and Larose É. (2014): Predictors and prognosis of early ischemic mitral regurgitation in the era of primary percutaneouscoronary revascularisation. Cardiovascular Ultrasound, 12:14-18.

7. Mehrnoush T, Sakineh $H$ and Afshin $H$. (2018): Correlation between echocardiographic severity of ischemic mitral valve regurgitation following acute myocardial infarction and its electrocardiographic location. J Cardiovasc Thorac Res., 10(3): 169-173.

8. Mentias A, Raza MQ, Barakat AF, Hill E, Youssef D and Krishnaswamy $A$. (2016): Outcomes of ischaemic mitral regurgitation in anterior versus inferior $\mathrm{ST}$ elevation myocardial infarction. Open Heart, 3(2):88-93.

9. Meris A, Amigoni M, Verma A, Thune J and Køber L. (2012): Mechanisms and 
Predictors of Mitral Regurgitation after High-Risk Myocardial Infarction. J Am Soc Echocardiogr., 25(5): 535-542.

10.Nishimura RA, Otto CM, Bonow R, Carabello BA, Erwin JP, Guyton RA, O'Gara PT, Ruiz CE, Skubas NJ, Sorajja P, Sundt TM and Thomas JD. (2014): AHA/ACC Guidelines for the management of patients with valvular heart disease: a report of the American College of Cardiology/American Heart Association task force on practice guidelines. Circulation, 129:521-643.

11.Pant S, Neupane P, Pant OB, Paudel R, Kavin Kumar MP and Vijayashankar CS. (2011): Mild Functional Ischemic Mitral Regurgitation Following Acute Coronary Syndrome: A Retrospective Study. Heart Views, 12:93-8.

12.Poh KK, Lee GK and Lee LC. (2012): Reperfusion therapies reduce ischemic mitral regurgitation following inferoposterior ST-segment elevation myocardial infarction. Coronary Artery Disease., 23: 555-559.

13.Thomas H Marwick, Patrizio Lancellotti and Luc Pierard. (2010): Ischaemic mitral regurgitation: Mechanisms and diagnosis. Heart, 95: 1711-8.

14.Uddin AM, Henry TD and Hodges JS. (2012): The prognostic role of mitral regurgitation after primary percutaneous coronary intervention for acute STelevation myocardial infarction. Catheter Cardiovasc Interv., 80:779-86.

15.Valuckienė $\check{Z}$, Urbonaitė $D$ and Jurkevičius R. (2015): Functional (ischemic) mitral regurgitation in acute phase of myocardial infarction: Associated clinical factors and in hospital outcomes. Medicina (Kaunas), 51(2):92-9. 


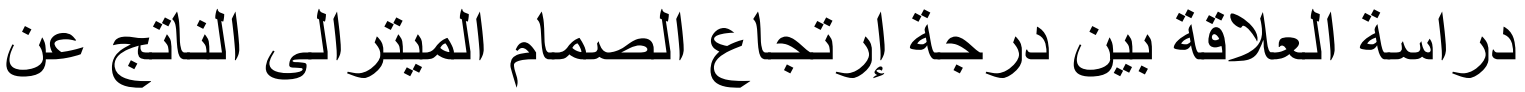 جلطة القلب الحادة بالموجات الصوتية على القلب الب ورسم القلب الكهربائي}

محمد جمال عبد العظيه, ياسر رضوان محمد, ياسر السيد محمد قسم أمراض القلب والأوعية الاموية, كلية الطب, جامعة الأزهر

E-mail: $\underline{\text { mohamed_gamal@gmail.com }}$

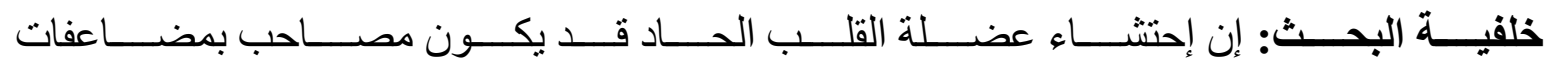

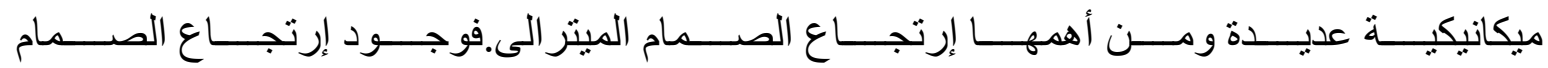

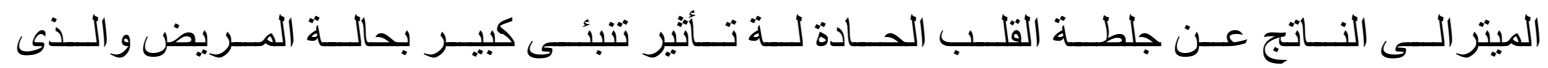

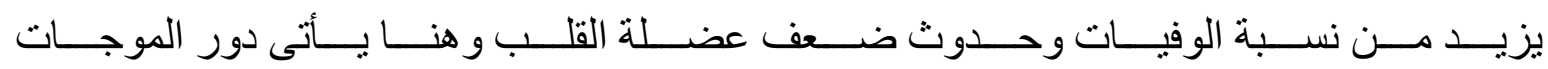
الصوتية على القلب و الدوبلر فى تثخيص هذا الإرتجاع وتحديد درجة شدته.

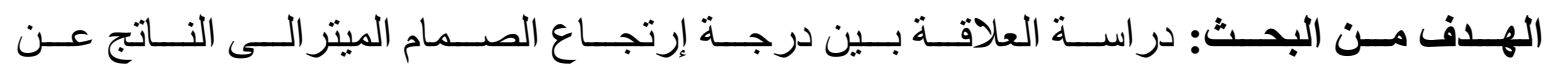
جلطة القلب الحادة بالموجات الصوتية على القلب ورسم القلب الكهربائى.

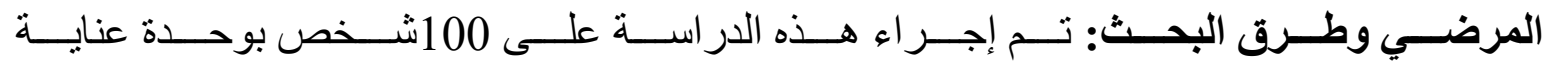

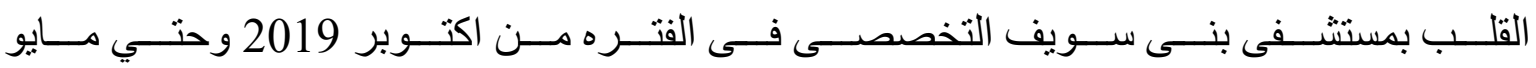
2020 وتم تقسيمهم إلي مجمو عتين متساو يتين: بنين

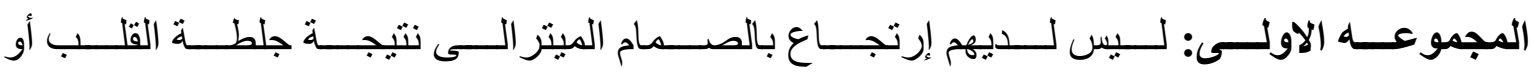
إرتجاع طفيف.

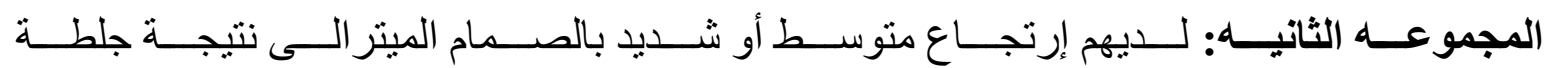
القلب.

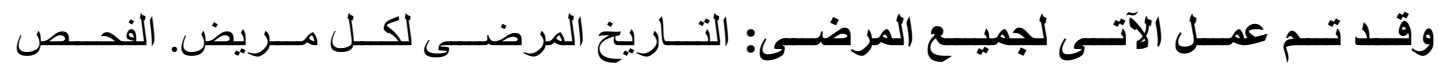

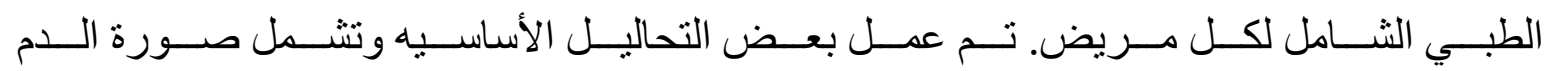

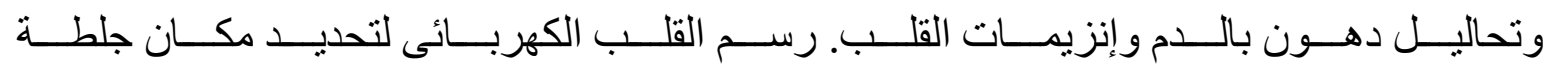

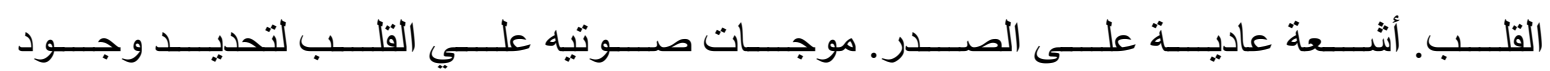
الإرتجاع بالصمام الميتر الى ودرجة شدنه. 


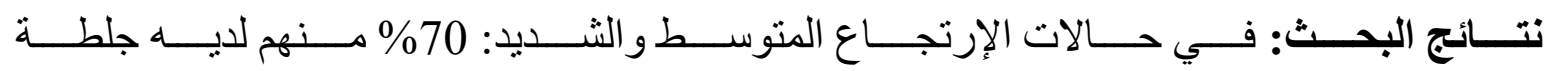

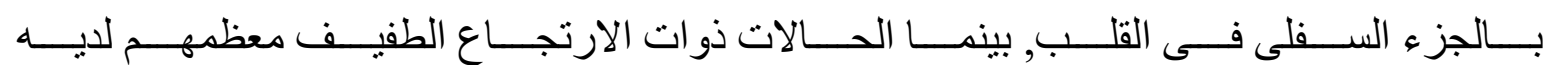

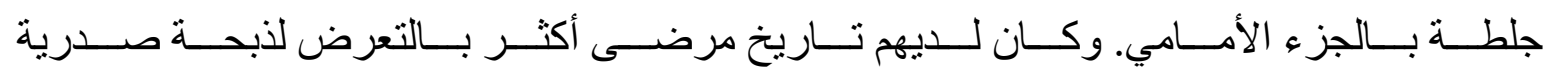

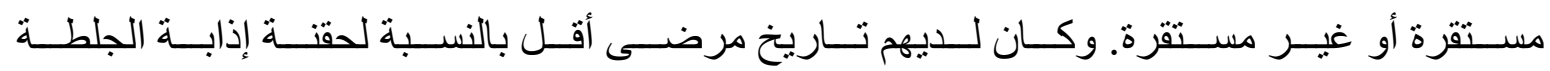

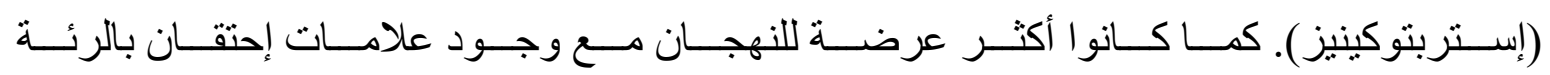

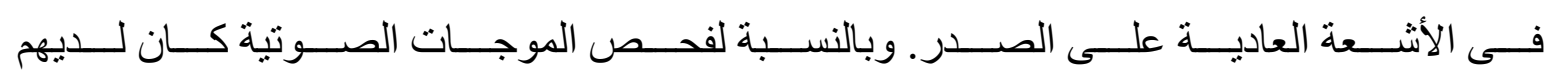

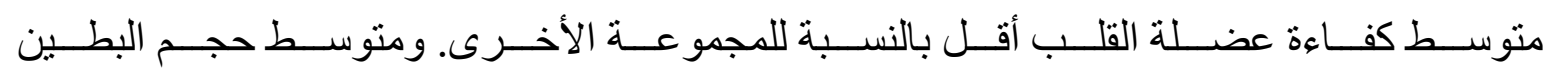

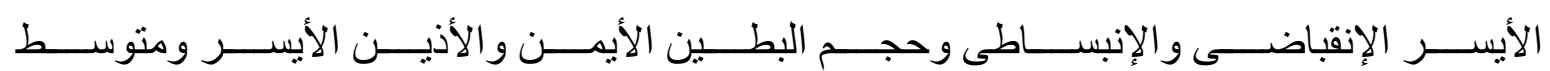

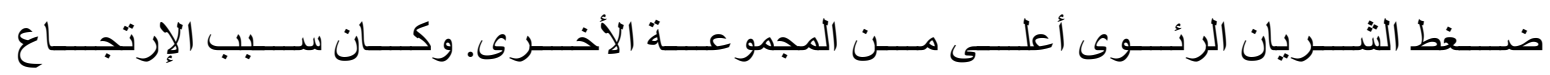

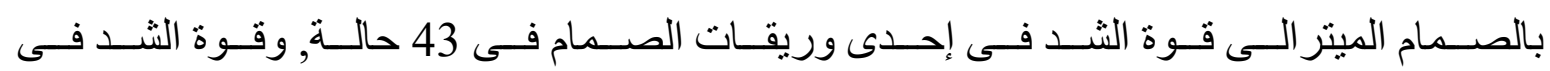

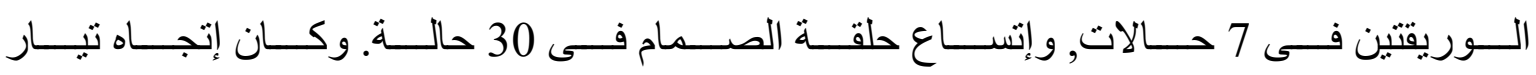

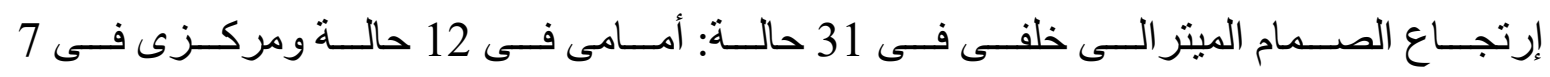
حالات.

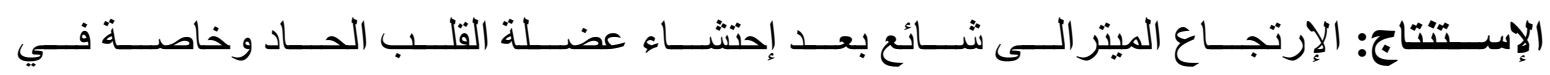

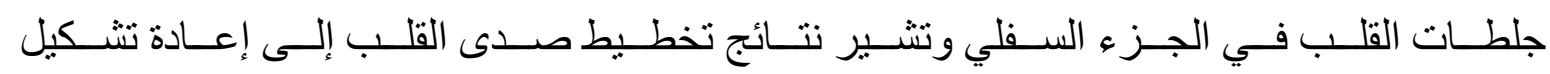
البطين الأيسر وشذوذ في جهاز الصمام التاجي.

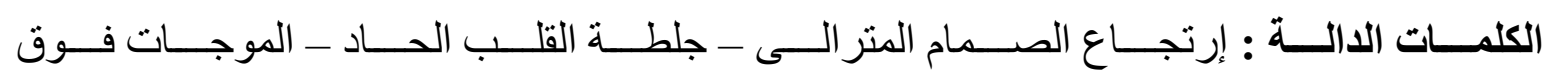
الصوتية 